\title{
QUANTITATIVE REAL-TIME PCR ASSAY FOR DIFFERENTIATION BETWEEN PNEUMOCYSTIS PNEUMONIA AND PNEUMOCYSTIS COLONIZATION
}

\author{
SINGH S. ${ }^{1}$, MIRDHA B.R. ${ }^{1 *}$, SINGH P. ${ }^{1}$, GULERIA R. ${ }^{2}$, MOHAN A. ${ }^{2}$, AGARWAL S.K. ${ }^{3}$, KABRA S.K. ${ }^{4}$ AND \\ PANDEY R.M. ${ }^{5}$
}

1Department of Microbiology, All India Institute of Medical Sciences (AlIMS), Ansari Nagar, New Delhi- 110 029, India. 2Department of Pulmonary Medicine and Sleep Disorders, All India Institute of Medical Sciences (AlIMS), Ansari Nagar, New Delhi- 110029 , India.

3Department of Nephrology, All India Institute of Medical Sciences (AlIMS), Ansari Nagar, New Delhi- 110029 , India. 4Department of Paediatrics, All India Institute of Medical Sciences (AIIMS), Ansari Nagar, New Delhi- 110 029, India. 5Department of Biostatistics, All India Institute of Medical Sciences (AIIMS), Ansari Nagar, New Delhi- 110 029, India. *Corresponding Author: Email- mirdhabr@gmail.com

Received: April 02, 2014; Accepted: May 06, 2014

\begin{abstract}
Pneumocystis jirovecii is a life threatening opportunistic pathogen among immunocompromised individuals. In the present study we evaluated the applicability of quantitative PCR (qPCR) assays for differentiation among diseased and colonized individuals with a diagnosis of PCP. A total of 355 patients were investigated with clinical suspicion of PCP, from whom 244 BALF and 111 induced sputum samples were obtained.

All these specimens were subjected to microscopy using GMS staining, c-PCR assay and qPCR assay. 80 patients were found positive for PCP. The relevant clinical, microbiological and radiological information was available only for 68 patients and were further categorized into definite $(n=12)$, probable $(n=47)$ and colonizers $(n=09)$ with $P$. jirovecii. The copy numbers, determined by qPCR assay, were significantly higher in definite PCP and probable PCP patients compared to colonizers. The AUC, sensitivity, and specificity for differentiating definite PCP from colonizers were $1.00,100.0 \%$, and $89.0 \%$, respectively, at a cut-off value of 13950 copies $/ \mathrm{mL}$. The values for discriminating probable PCP from colonization were, $0.81,72 \%$ and $78 \%$ respectively, at a cut-off value of 6580 copies $/ \mathrm{mL}$. However, the AUC, sensitivity, and specificity were $0.85,75 \%$ and $78 \%$ respectively when colonizers were differentiated from both definite - probable PCP taken together, with a cutoff 7015 of copies/ml. Thus, there was an overlap between cut-off for probable PCP patients and colonizers. Therefore, the present study demonstrated that qPCR assay could be useful for discriminating definite PCP with colonizers, but had limitation for distinguishing between probable PCP from colonizers.
\end{abstract}

Keywords- PCP, qPCR, definite PCP, probable PCP and colonizers with P. jirovecii.

Citation: Singh S., et al. (2014) Quantitative Real-time PCR Assay for Differentiation between Pneumocystis Pneumonia and Pneumocystis Colonization. International Journal of Medical and Clinical Research, ISSN: 0976-5530 \& E-ISSN: 0976-5549, Volume 5, Issue 1, pp.-286-293.

Copyright: Copyright@2014 Singh S., et al. This is an open-access article distributed under the terms of the Creative Commons Attribution License, which permits unrestricted use, distribution and reproduction in any medium, provided the original author and source are credited.

\section{Introduction}

Pneumocystis jirovecii the causative agent of Pneumocystis pneumonia (PCP) is cosmopolitan in distribution. PCP remains one of the leading causes of morbidity and mortality especially among human immunodeficiency virus (HIV) infected individuals [1]. In addition to that among non-HIV immunocompromised patients with underlying conditions such as organ transplantation recipients receiving immunosuppressive therapies, various autoimmune disorders and patients with malignant disorders and on chemotherapeutic agents predispose them to PCP [2].

Confirmatory diagnosis of PCP mainly relies on the microscopic demonstration of cystic or trophic forms of Pneumocystis jirovecii in respiratory clinical samples [3]. As the clinical presentations of PCP among HIV and non-HIV immunocompromised patients differed a lot. Non-HIV immunocompromised patients often experience an abrupt onset of symptoms and with a shorter duration of symptoms prior to seeking medical evaluation, and rarely develop cystic lung disease $[2,4,5]$. Besides this, the burden of organism among HIV infected individuals is higher than that among non-HIV immunocompromised individuals [6]. Furthermore, the load of the organism may also vary with the type of the respiratory clinical samples. Hence, microscopic demonstration of $P$. jirovecii suffers with the problem of limited sensitivity and resulting in false negativity especially among non-HIV immunocompromised individuals [7].

To circumvent, the limitations of lower sensitivity and high negative predictive value of microscopy, a highly sensitive molecular diagnostics such as PCR assay has been studied extensively for the detection of $P$. jirovecii specific DNA from the clinical samples in patients with high index of clinical suspicion of PCP.

However, sometimes it has been encountered that patients without 
having overt clinical feature suggestive of PCP may be positive for $P$. jirovecii specific DNA by PCR based assays. Such cases have been termed as 'Sub-clinical infection' or 'Colonization with $P$. jirovecii.'

In such patients it is often difficult to distinguish between PCP diseased and colonization with $P$. jirovecii using conventional PCR assays. Hence, a quantitative PCR is required to know the load of organism in the clinical sample to stratify the diseases spectrum. Larsen, et al [8], Huggett, et al [9], and in recent time, Matsumura, et al [10], proposed that the copy number of the specific $P$. jirovecii gene used for quantitation was found to be substantially higher in patients with PCP than in colonized individuals.

In this study, we aimed to assess the applicability of quantitative PCR (qPCR) assay to differentiate among definite PCP, probable $\mathrm{PCP}$ and colonizers with $P$. jirovecii.

\section{Materials and Methods}

The present study was conducted at the Parasitology Laboratory, Department of Microbiology, All India Institute of Medical Sciences (AlIMS), New Delhi, India.

\section{Patients and Clinical Samples}

During the 5 year study period (Feb 2007 to Dec 2012), a total of 355 patients including both HIV sero positive and non-HIV immunocompromised individuals with pulmonary infection clinically suggestive of PCP attending to various OPD and/or admitted to our tertiary care centre were enrolled.

Among these 355 patients, 106 were HIV seropositive patients $(n=106)$ and remaining 249 were non-HIV immunocompromised patients. These non-HIV immunocompromised patients were further subdivided into post-renal transplant (PRT) recipients $(n=66)$, cancer patients on chemotherapy $(n=84)$, patients with various primary immunodeficiencies, and autoimmune disorders $(n=99)$. From these 355 patients, equal number of $(n=355)$ samples were obtained that included, 244 bronchoalveolar lavage (BALF) fluid and 111 induced sputum (IS).

Demographic profile, clinical characteristics, laboratory findings and radiological findings of each patient were collected prospectively during the course of study.

\section{Clinical Sample Processing and DNA Extraction}

All the BAL fluid samples were directly centrifuged at $4000 \mathrm{rpm}$ at $4^{\circ} \mathrm{C}$ for $10 \mathrm{~min}$. However, induced sputum samples were first treated with $6.5 \mathrm{mM}$ dithiothreitol (DTT), a mucolytic agent and then subjected to centrifugation. The pellet obtained was resuspended in $20 \%$ of the supernatant and $100 \mu \mathrm{l}$ of this suspended pellet was used for preparation of smears.

For DNA extraction, $200 \mu \mathrm{l}$ of pellet was lysed using $200 \mu \mathrm{l}$ of a sample-specific lysis buffer $(50 \mathrm{mM} \mathrm{KCl}, 15 \mathrm{mM}$ Tris- $\mathrm{HCl}(\mathrm{pH} 8.3)$ and $0.5 \%$ NP 40 ) [11] containing $500 \mathrm{mg}$ of proteinase K. DNA extraction was performed using Qiagen DNeasy tissue kit (Qiagen Inc., Valencia, CA, USA).

\section{Microscopic Detection}

Smears were prepared from all the samples. Smears were stained using Grocott's methenamine silver (GMS) staining. All the stained slides were examined by two experienced microbiologists independently without prior knowledge of PCR results.

\section{Conventional PCR (c-PCR) Assay}

C-PCR was performed using highly conserved region of mitochondrial large sub-unit ribosomal RNA (mtLSU rRNA) gene of $P$. jirovecii. The following set of published primers pAZ $102 \mathrm{E}$ and $\mathrm{pAZ}$ $102 \mathrm{H}$ [12], were used that amplify a $346 \mathrm{bp}$ region of the gene.

\section{Real-time PCR (qPCR) Assay}

DNA extracted from all the clinical samples were subjected to qPCR assay targeting the single copy gene Beta-tubulin gene.

The set of primers used were as described by Nahimana, et al [13] and Brancart, et al [14] for c-PCR and qPCR respectively targeting Beta-tubulin gene. However, the probe used was with slight modification. The probe was FAM - MGB labeled, with the product size of $74 \mathrm{bp}$. The sequences of forward and reverse primers; and probe used were as follows F-(1186-5') GATCCGAGACATGGTCGCTATT, R-(1257-5') TTCAACCTCCTTCATGGAAACAG and P(1217T-5') FAM-CAGCGATTTTCCGCGGTA- MGB, for the Accession No. AF170964.

The qPCR assay was performed in a $25 \mu$ reaction volume containing $0.9 \mu \mathrm{M}$ each primer, $0.25 \mu \mathrm{M}$ TaqMan probe, $1 \times$ TaqMan Gene Expression Master Mix [Applied Biosystems, (ABI)], and $5 \mu$ purified DNA. The thermal cycling was performed at universal conditions in an ABI PRISM 7500 Sequence Detection system (ABI) and that were as follows: $2 \mathrm{~min}$ at $50^{\circ} \mathrm{C}, 10 \mathrm{~min}$ at $95^{\circ} \mathrm{C}$, followed by 45 cycles of $15 \mathrm{~s}$ at $95^{\circ} \mathrm{C}$ and $1 \mathrm{~min}$ at $60^{\circ} \mathrm{C}$.

Quantification was performed using ABI PRISM software and was based on the extrapolation of data to standard curves, which were generated by the amplification of a 10 -fold serial dilution of a plasmid standard $\left(10 \times 10^{6}\right.$ to 10 copies/reaction). To generate the plasmids, the c-PCR-amplified product of $209 \mathrm{bp}$ was cloned into the $\mathrm{p}$ GEMT Easy vector and was confirmed by colony PCR assay, restriction digestion and sequencing (Data not shown). A Ct value above 40 was not considered as positive for the presence of $P$. jirovecii specific DNA. The final results of qPCR were expressed as copy numbers of Pneumocystis jirovecii per $\mathrm{ml}$ of sample.

\section{Diagnosis of PCP}

On the basis of available clinical information, microscopic, c-PCR assay results and the definitions that have been described earlier were adopted to stratify the $P$. jirovecii positive patients into definite PCP, probable PCP and colonizers with $P$. jirovecii.

The diagnosis of definite PCP was established by the microscopic identification of $P$. jirovecii using Gomori methenamine silver staining. A diagnosis of probable PCP was made when the patient did not have microscopically visible $P$. jirovecii but had a clinical presentation compatible with PCP, including complete resolution of pulmonary infiltrates after a full course of anti-PCP treatment [7]. However, "colonization with $P$. jirovecii" was defined as the patients who had positive PCR results without any signs or symptoms of PCP and who improved without anti-PCP treatment were diagnosed as "pneumonia with $P$. jirovecii colonization" [15].

\section{Demographic and Clinical Information}

The relevant demographic and clinical information including age, sex, underlying diseases, immunosuppressive therapies and prophylaxis and treatment for PCP, clinical symptoms, laboratory values, the final diagnosis made and the treatment for the final diagnosis and co-infection. ABG values, ICU admission and requirement of mechanical ventilation were also obtained along with hema- 
tological profile of the patients were included in the study.

\section{Statistical Analysis}

Categorical variables were compared using the Fisher exact t-test. Continuous variables were compared using the Kruskal-Wallis t-test or the Mann-Whitney $U$ test. Receiver-operating characteristic (ROC) curves for the copy numbers were constructed and studied between three different groups i.e. 'definite PCP' and 'colonizers', 'probable PCP' and 'colonizers' and 'definite PCP-probable PCP' together and 'colonizers'. Areas under the curve (AUC) of the three ROC curves were analyzed as already described by Delong, et al [16]. A $p$ value $<0.05$ was considered statistically significant. All statistical analyses were carried out using SPSS software version 16 (SPSS, USA).

\section{Results}

From 355 patients enrolled, there were only 80 patients positive for $P$. jirovecii specific DNA using qPCR assay and were included for the further analysis. The additional four patients that were positive by C-PCR and negative by qPCR were considered negative for $P C P$. Thus, the remaining 275 patients were considered as negative for PCP. The demographics profile and clinical characteristics of PCP positive and negative patients were shown in [Table-1].

Table 1- Comparison of demographic and clinical characteristics of PCP positive $(n=80)$ and PCP negative patients $(n=275)$ under study $(n=335)$

\begin{tabular}{lccc} 
Characteristics & $\begin{array}{c}\text { PCP -ve } \\
(n=275)\end{array}$ & $\begin{array}{c}\text { PCP +ve } \\
(n=80)\end{array}$ & -value \\
Sex (Male / female) & $189 / 86$ & $59 / 21$ & 0.28 \\
Age (Mean \pm S.D) & $22.09 \pm 19.78$ & $25.94 \pm 20.12$ & 0.001 \\
Fever (no.\%) & 194 & 76 & 0.0001 \\
& $(70.3 \%)$ & $(94.9 \%)$ & \\
Cough (no.\%) & 188 & 66 & 0.01 \\
& $(68.1 \%)$ & $(82.3 \%)$ & \\
Dyspnoea (no.\%) & 181 & 76 & 0.001 \\
& $(65.6 \%)$ & $(94.9 \%)$ & \\
Abnormal CXR Findings (no.\%) & 228 & 80 & 0.0001 \\
& $(82.6 \%)$ & $(100 \%)$ & \\
PCP prophylaxis with sulpha (no.\%) & 43 & 18 & 0.16 \\
& $(15.6 \%)$ & $(22.7 \%)$ & \\
Anti-PCP treatment (no.\%) & 87 & 71 & 0.000 \\
ICU admissions (no.\%) & $(31.6 \%)$ & $(94.9 \%)$ & \\
& 42 & 22 & 0.01 \\
Mechanical ventilation (no.\%) & $(15.2 \%)$ & $(27.8 \%)$ & \\
& 40 & 22 & 0.01 \\
\hline
\end{tabular}

ICU: Intensive Care Unit; $\mathrm{PaO}_{2}$ : Arterial Partial Pressure of Oxygen; CXR: Chest X-ray

On comparing demographic and clinical characteristics the mean age of PCP positive patients was observed to be $25.94 \pm 20.12$, while the mean age of PCP negative patients was $22.09 \pm 19.78$, ( $p$ $\leq 0.001$, [Table-1]). There were no significant differences when the male to female ratio of PCP positives and negatives patients were compared. Anti-Pneumocystis prophylaxis with sulfa drugs could be documented only in $15.6 \%$ (43/275) of PCP negative patients and $22.5 \%$ (18/80) of PCP positive patients and were found to be statistically non-significant in occurrence of PCP. However, dyspnoea $(p=0.01)$ and abnormal CXR/CT findings $(p=0.001)$ were significantly associated with PCP positive patients compared to PCP negatives. In addition, ICU admission and mechanical ventilation were also found to be significantly associated with PCP positive patients compared to negatives $(p=0.01)$.

All these $80 \mathrm{c}-\mathrm{PCR}$ and $\mathrm{qPCR}$ assay positive patients were further stratified into definite PCP $(n=14)$, probable PCP $(n=54)$ and colonizer $(n=12)$ with $P$. jirovecii as per the criteria defined above. As the detailed clinical and laboratory findings could be obtained only for $68(85.00 \%, 68 / 80)$ of these 80 patients, therefore, these 68 patients were included for the final analyses. These 68 PCP positive patients were stratified into 'definite PCP' $(n=12)$, 'probable PCP' ( $n=47)$ and 'colonizers' with $P$. jirovecii $(n=09)$ [Table-2]. Demographic profiles and clinical characteristics of these definite PCP, probable PCP and colonizer were also analyzed. Among them 49 were male and 19 were female. Definite group of patients comprised of one $(n=1)$ HIV infected individuals, nine $(n=9)$ PRT recipients and two $(n=2)$ from other immunocompromised conditions respectively. Probable group of patients included eighteen $(n=18)$ HIV infected individuals, eight $(n=08)$ PRT recipients, seven $(n=07)$ patients were with malignant disorders and two $(n=02)$ from other immunocompromised conditions. Only nine individuals belongs to colonizers that included two $(n=02)$ PRT recipients, one $(n=01)$ patient with malignant disorders and six $(n=06)$ from other immunocompromised conditions.

The final diagnosis among colonizers included CMV infection among both the PRT patients, Mycobacterium tuberculosis was present among four $(n=04)$ of these patients and two were having Candida albicans along with $M$. tuberculosis. Pseudomonas species was present in one of them and bacterial pneumonia with Staphylococcus aureus $(n=01)$, Streptococcus pneumoniae $(n=01)$ and Haemophilus influenzae $(n=01)$ was also present as the primary pneumonia causing agent. None of these colonizers developed clinical PCP during the same episode of hospitalization for pneumonia and followed up for a period of 42 days.

Clinical characteristics of definite PCP, probable PCP and colonizers were statistically evaluated. Both dry cough and cough with expectoration were found to be significant. The persistence of dry cough was found to be $92 \%$ associated with definite PCP patients followed by $48.9 \%$ in probable PCP group. Expectorated cough was predominantly $(78 \%)$ associated with colonizers. BAL fluid sample was extremely useful for the diagnosis of definite PCP (92\%) and colonizers (100\%). Whereas, sputum samples could detect only $49 \%$ probable PCP.

However, fever, dyspnoea, abnormal CXR, respiratory rate, partial pressure of oxygen, ICU admission and mechanical ventilation when compared among these three groups were not statistically significant [Table-2]. Analyses of laboratory findings revealed that only hemoglobin $(\mathrm{Hb} \%)$, serum phosphate and serum sodium were significant, while other parameters were non-significant [Table-3].

Upon analyses of various therapeutics regimens given, 34 (50\%) out of 68 patients were on corticosteroids, that included $08(66 \%)$, $19(40.4 \%)$ and 07 (78\%) from definite PCP, probable PCP and colonizer groups respectively. Twenty two $(22 / 68,32.4 \%)$ of total individuals were on immunosuppressive drugs. There were 07 $(10.3 \%)$ patients who were on chemotherapy and all of them were from definite and probable group. All of these colonizers neither received anti-PCP prophylaxis nor anti-PCP treatment.

Anti-PCP prophylaxis and administration of TMP-SMX treatment was found to be statistically significant $(p=0.002, p=0.000)$ with definite and probable PCP group of patients [Table-4]. 
Table 2- Demographic and clinical profile of definite PCP, probable PCP and colonizers $(n=68)$

\begin{tabular}{|c|c|c|c|c|c|}
\hline Characteristics & Total $(n=68)$ & Definite PCP $(n=12)$ & Probable PCP $(n=47)$ & Colonizers $(n=09)$ & p-value \\
\hline Age Median (min-max) & $25.5(1-74)$ & $44.5(1-74)$ & $18(1-71)$ & $28(14-53)$ & 0.01 \\
\hline Sex (Male / Female) & $49 / 19$ & $10 / 02$ & $33 / 14$ & $06 / 03$ & 0.70 \\
\hline \multicolumn{6}{|c|}{ Underlying Conditions } \\
\hline HIV positive (no.\%) & 19/68 (27.9\%) & $01(8.3 \%)$ & $18(38.2 \%)$ & $0(00 \%)$ & 0.01 \\
\hline PRT recipients (no.\%) & $19 / 68(27.9 \%)$ & $09(75 \%)$ & $08(17 \%)$ & $02(22.2 \%)$ & 0.00 \\
\hline Malignant disorders (no.\%) & 08/68 (11.8\%) & $00(00 \%)$ & $07(14.8 \%)$ & $01(11.1 \%)$ & 0.43 \\
\hline Others immunocompromised conditions (no.\%) & $22 / 68(32.8 \%)$ & $02(16.6 \%)$ & $14(29.7 \%)$ & $06(66.6 \%)$ & 0.04 \\
\hline \multicolumn{6}{|c|}{ Clinical characteristics } \\
\hline Fever (no.\%) & $65 / 68(95.6 \%)$ & $12(100 \%)$ & $44(100 \%)$ & $09(100 \%)$ & 1.00 \\
\hline Cough (no.\%) & $61 / 68(89.7 \%)$ & $12(100 \%)$ & $40(85.1 \%)$ & $09(100 \%)$ & 0.30 \\
\hline a. Dry Cough (no.\%) & $36 / 68(52.9 \%)$ & $11(92 \%)$ & $23(48.9 \%)$ & $02(22.2 \%)$ & 0.003 \\
\hline b. Cough with expectoration (no.\%) & $25 / 68(36.8 \%)$ & $01(8.3 \%)$ & $17(36.1 \%)$ & $07(77.7 \%)$ & 0.004 \\
\hline Dyspnoea (no.\%) & $57 / 68(83.8 \%)$ & $10(83.3 \%)$ & $41(87.2 \%)$ & $06(66.6 \%)$ & 0.27 \\
\hline Abnormal CXR (no.\%) & $68 / 68(100 \%)$ & $12(100 \%)$ & $47(100 \%)$ & $09(100 \%)$ & NA \\
\hline Respiratory rate Median (min-max) & $30(16-56)$ & $28(18-44)$ & $32(16-56)$ & $30(18-36)$ & 0.22 \\
\hline $\mathrm{PaO}_{2}$ Median (min-max) & $54.6(42.4-66.4)$ & $54.6(46.8-62.2)$ & $54(42.4-66.4)$ & $56.2(46-62.2)$ & 0.29 \\
\hline ICU admission (no.\%) & $21 / 68(30.9 \%)$ & $02(16.6 \%)$ & $18(38.2 \%)$ & $01(11.11 \%)$ & 0.15 \\
\hline Mechanical ventilation (no.\%) & $21 / 68(30.9 \%)$ & $02(16.6 \%)$ & $18(38.2 \%)$ & $0(11.11 \%)$ & 0.15 \\
\hline
\end{tabular}

$\mathrm{HIV}^{*}$ : Human Immunodeficiency Virus; PRT ${ }^{* *}$ : Post Renal Transplant; ICU; Intensive Care Unit; $\mathrm{PaO}_{2}$; Arterial partial pressure of oxygen; CXR: Chest X-ray. Others immunocompromised conditions: Cushing's syndrome $(n=02)$; Primary Immunodeficiency $(n=01)$; Langerhan's cell histiocytosis ( $n=01)$; Bone marrow transplant recipient ( $n=02)$; Systemic lupus erythematosus $(n=03)$; Pulmonary alveolar proteinosis $(n=03)$; Post liver transplant $(n=01)$; Wegner's granulomatosis $(n=01)$; Hyper lgM syndrome ( $n=02)$; Hyper lgG syndrome ( $n=02)$; Steroid-dependent nephrotic syndrome (SDNS) ( $n=01$ ); Maple's syrup urine disease $(n=01)$; Metabolic acidiosis $(n=01)$; Autoimmune related cirrhosis $(n=01)$.

\begin{tabular}{|c|c|c|c|c|c|}
\hline $\begin{array}{l}\text { Laboratory findings } \\
\text { measurement units Median [ } \mathrm{min} \text { - max] }\end{array}$ & $\begin{array}{c}\text { Total } \\
(n=68)\end{array}$ & $\begin{array}{l}\text { Definite PCP } \\
\quad(n=12)\end{array}$ & $\begin{array}{l}\text { Probable PCP } \\
(n=47)\end{array}$ & $\begin{array}{l}\text { Colonizers } \\
(n=09)\end{array}$ & $p$ - value \\
\hline $\mathrm{Hb}$ (gms/dl) & $9.55(5.8-12.9)$ & $9.7(8.2-12.7)$ & $8.7(5.8-12.9)$ & $10.1(8.2$ - 12.7) & 0.01 \\
\hline TLC (10 3/ cu. mm.) & $7.6(6-21)$ & $8.1(4.7-17.1)$ & $8.4(.6-21)$ & $6.9(3.8-8.6)$ & 0.32 \\
\hline Platelets (10 3/ cu.mm.) & $194.5(2.78-575)$ & $200(2.78-564)$ & $189(16-575)$ & $196(23-300)$ & 0.65 \\
\hline Serum urea (mg.\%) & $29.5(7.2-236)$ & $38(7.2-236)$ & $28(14-200)$ & $25(20-56)$ & 0.11 \\
\hline Serum creatinine (mg.\%) & $0.9(.4-8.8)$ & $1.6(.4-5.6)$ & $.8(.4-8.8)$ & $.9(.4-2.7)$ & 0.27 \\
\hline Serum calcium (mg.\%) & $8.6(1.0-9.8)$ & $8.6(7.4-9.1)$ & $8.4(1.0-9.8)$ & $8.6(7.2-9.8)$ & 0.50 \\
\hline Serum phosphate (mg.\%) & $3.95(2.4-136.0)$ & $4.3(3.3-5.8)$ & $3.9(2.4-5.8)$ & $4.0(3.0-136)$ & 0.001 \\
\hline Serum sodium (mEq / $\mathrm{L}$ ) & $136(124-147)$ & $136(124-139)$ & $13(126-147)$ & $135(124-146)$ & 0.05 \\
\hline Serum potassium (mEq / L) & $3.9(2.4-5.6)$ & $3.9(3.1-5.6)$ & $3.9(2.4-5.2)$ & $4.0(2.7-4.9)$ & 0.55 \\
\hline Serum uric acid (mg.\%) & $4.3(1.5-12.6)$ & $5.4(2.9-12.6)$ & $4.1(1.5-12.4)$ & $4.8(3.1-12.4)$ & 0.17 \\
\hline Serum bilirubin (mg.\%) & $0.6(0.3-2.6)$ & $0.6(0.5-1.2)$ & $0.6(0.3-2.6)$ & $0.6(0.3-1.3)$ & 0.64 \\
\hline Serum total protein (gm.\%) & $6.8(4.1-88)$ & $6.2(4.9-8.8)$ & $6.8(4.1-8.8)$ & $6.0(5.4-7.8)$ & 0.39 \\
\hline Serum albumin (gm.\%) & $3.5(1.1-4.8)$ & $3.4(2.8-4.0)$ & $3.5(1.1-4.8)$ & $3.4(2.7-4.2)$ & 0.98 \\
\hline Serum globulin (gm.\%) & $3.1(2.0-5.9)$ & $3.1(2.0-4.8)$ & $3.2(2.0-5.9)$ & $2.8(2.0-4.0)$ & 0.25 \\
\hline BALF (no.\%) & $44(64.7 \%)$ & $11(92 \%)$ & $24(51 \%)$ & $09(100 \%)$ & 0.001 \\
\hline Sputum (no.\%) & $24(35.3 \%)$ & $01(8.3 \%)$ & $23(49 \%)$ & $00(00 \%)$ & 0.001 \\
\hline $\begin{array}{l}\text { Beta tubulin(copy no. / ml) } \\
\text { Median [min - max] }\end{array}$ & $\begin{array}{c}16000 \\
(152-1430000)\end{array}$ & $\begin{array}{c}395500 \\
(53700-1430000)\end{array}$ & $\begin{array}{c}14100 \\
(200-620000)\end{array}$ & $\begin{array}{c}1990 \\
(152-15300)\end{array}$ & 0.000 \\
\hline
\end{tabular}

TLC: Total leucocytes count; BALF: Bronchoalveolar lavage fluid; Hb: Hemoglobin 
Singh S., Mirdha B.R., Singh P., Guleria R., Mohan A., Agarwal S.K., Kabra S.K. and Pandey R.M.

Table 4- Immunosuppressive therapies and various prophylactic and treatment regimens administered to PCP patients $(n=68)$

\begin{tabular}{|c|c|c|c|c|c|}
\hline Various Regimens & $\begin{array}{c}\text { Total } \\
(\mathrm{n}=68)\end{array}$ & $\begin{array}{l}\text { Definite PCP } \\
\quad(n=12)\end{array}$ & $\begin{array}{c}\text { Probable PCP } \\
\qquad(n=47)\end{array}$ & $\begin{array}{l}\text { Colonizers } \\
(n=09)\end{array}$ & p-value \\
\hline Corticosteroids (no.\%) & $\begin{array}{l}34 / 68 \\
(50 \%)\end{array}$ & $\begin{array}{c}08 \\
(66.6 \%)\end{array}$ & $\begin{array}{c}19 \\
(40.4 \%)\end{array}$ & $\begin{array}{c}07 \\
(78 \%)\end{array}$ & 0.06 \\
\hline Other Immuno-suppressive drugs (no.\%) & $\begin{array}{c}22 / 68 \\
(32.4 \%)\end{array}$ & $\begin{array}{c}06 \\
(50 \%)\end{array}$ & $\begin{array}{c}14 \\
(30 \%)\end{array}$ & $\begin{array}{c}04 \\
(44.4 \%)\end{array}$ & 0.38 \\
\hline Chemotherapy (no.\%) & $\begin{array}{c}07 / 68 \\
(10.3 \%)\end{array}$ & $\begin{array}{c}06 \\
(50 \%)\end{array}$ & $\begin{array}{c}01 \\
(2.1 \%)\end{array}$ & $\begin{array}{c}00 \\
(00 \%)\end{array}$ & 0.48 \\
\hline Anti- PCP prophylaxis (no.\%) & $\begin{array}{l}23 / 68 \\
(33.8)\end{array}$ & $\begin{array}{c}01 \\
(8.3 \%)\end{array}$ & $\begin{array}{c}22 \\
(47 \%)\end{array}$ & $\begin{array}{c}00 \\
(00 \%)\end{array}$ & 0.002 \\
\hline TMP-SMX (no.\%) & $\begin{array}{c}59 / 68 \\
(86.8 \%)\end{array}$ & $\begin{array}{c}12 \\
(100 \%)\end{array}$ & $\begin{array}{c}47 \\
(100 \%)\end{array}$ & $\begin{array}{c}00 \\
(00 \%)\end{array}$ & 0.00 \\
\hline Clindamycin (no.\%) & $\begin{array}{c}27 / 68 \\
(33.7 \%)\end{array}$ & $\begin{array}{c}07 \\
(58 \%)\end{array}$ & $\begin{array}{c}20 \\
(42.5 \%)\end{array}$ & $\begin{array}{c}00 \\
(00 \%)\end{array}$ & 0.01 \\
\hline Anti-CMV (Gancyclovir) (no.\%) & $\begin{array}{c}15 / 68 \\
(22.1 \%)\end{array}$ & $\begin{array}{c}03 \\
(25 \%)\end{array}$ & $\begin{array}{c}10 \\
(21.2 \%)\end{array}$ & $\begin{array}{c}02 \\
(22.2 \%)\end{array}$ & 0.90 \\
\hline ATT (no.\%) & $\begin{array}{c}19 / 68 \\
(27.9 \%)\end{array}$ & $\begin{array}{c}02 \\
(16.6 \%)\end{array}$ & $\begin{array}{c}13 \\
(27.6 \%)\end{array}$ & $\begin{array}{c}04 \\
(44.4 \%)\end{array}$ & 0.41 \\
\hline Anti-fungal treatment (no.\%) & $\begin{array}{c}20 / 68 \\
(29.4 \%)\end{array}$ & $\begin{array}{c}04 \\
(33.3 \%)\end{array}$ & $\begin{array}{c}14 \\
(30 \%)\end{array}$ & $\begin{array}{c}02 \\
(22.2 \%)\end{array}$ & 0.85 \\
\hline Antibiotics (no.\%) & $\begin{array}{l}17 / 68 \\
(25 \%)\end{array}$ & $\begin{array}{c}04 \\
(33.3 \%)\end{array}$ & $\begin{array}{c}08 \\
(17 \%)\end{array}$ & $\begin{array}{c}05 \\
(55.5 \%)\end{array}$ & 0.03 \\
\hline
\end{tabular}

awithin 3 months before present hospital visit/admission

${ }^{\wedge}$ ATT-Anti-Tuberculosis Treatment

${ }^{*}$ Corticosteroids: Prednisolone, Hydrocortisone, Methyl prednisolone

${ }^{* *}$ Other Immunosuppressive drugs: Cyclosporine, Mycophenolate, Tacrolimus, Azathioprine,

${ }^{* * *}$ Chemotherapy: Cyclophosphamide, Doxorubicin, Vincristine, Prednisone, Cisplatin, Etoposide

\#TMP-SMX- Trimethoprim/sulfamethoxazole

\section{Real time PCR (qPCR) Assay Analysis}

The standard curve was established with a plasmid control [Fig-1]. The GPCR assay showed a limit of detection of 50 copies $/ \mathrm{ml}$ and the $P$. jirovecii quantification found to be linear over a range of $5 \log _{10}$ of magnitude i.e from $10^{6}$ to $10^{2}$ copies/ $\mathrm{ml}$. The detection rate was $100 \%$ when the copy number was $>100$ copies $/ \mathrm{ml}$.

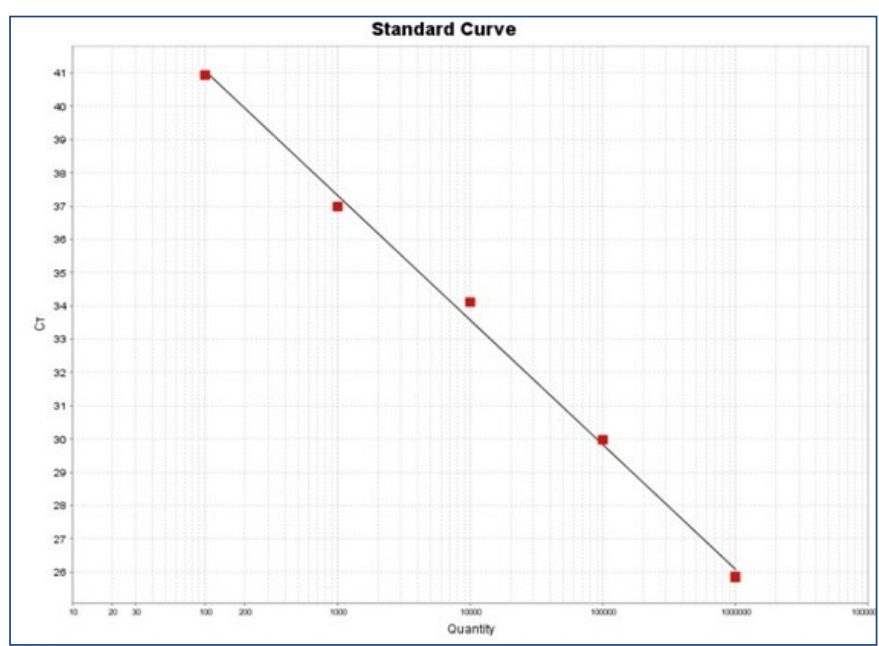

Fig. 1- Standard curve of Beta-tubulin gene

$X$ axis- Tenfold serial dilutions of cloned plasmid $\left(10^{6}-10^{1}\right)$

$Y$ axis- $C t$ value

The median of $P$. jirovecii copy numbers among definite PCP, probable PCP and colonizers were 395500, 14100 and 1990 copies $/ \mathrm{ml}$ respectively [Fig-2]. These findings clearly showed that the load of $P$. jirovecii was much higher in definite PCP group and was statisti- cally significant. Moreover, the comparisons between BALF and induced sputum samples were not done separately as there was no sputum sample among the colonizers.

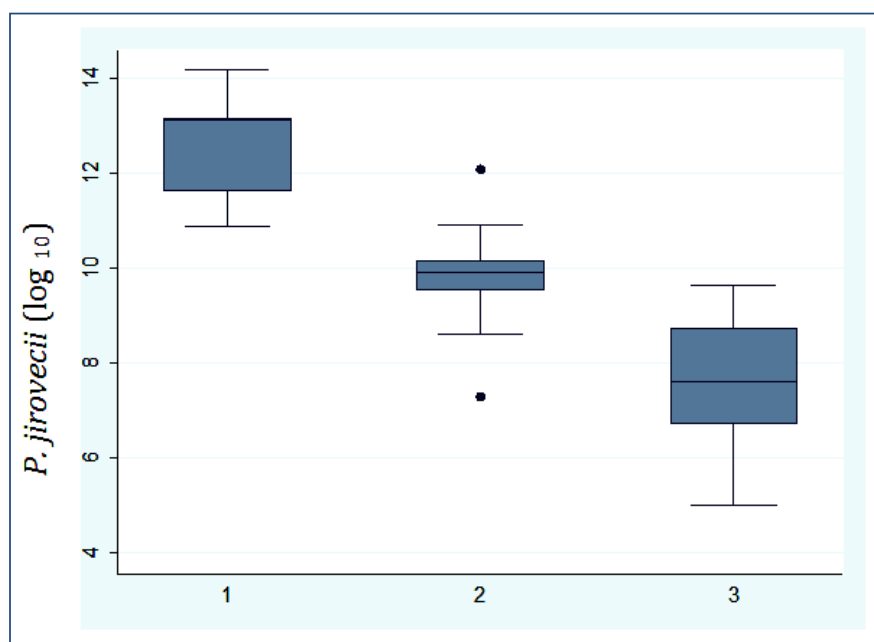

Fig. 2- Copy number $P$. jirovecii among positive samples $(n=68)$

Although the median value of copy numbers were analyzed in all 68 clinical samples. The Receiver Operating Characteristic (ROC) curve was constructed to ascertain the cut-off value to differentiate between definite PCP, probable PCP and colonizers among them.

In the present study, the arbitrary cut-off value of 13950 copies $/ \mathrm{ml}$ was used to differentiate definite PCP from colonizers i.e. patients having copies equal or more than 13950 copies $/ \mathrm{ml}$ were suggestive of definite PCP and less than 13950 copies/ml may be considered 
as colonizers. Cut-off value of 6580 copies $/ \mathrm{ml}$ was used to differentiate between probable PCP and colonizers. Patients having copy number equal to or less than 6580 may be considered as colonizer and copy number above 6580 indicated probable PCP. The area under curve (AUC), sensitivity, and specificity for discriminating definite PCP from colonizer was 1 with sensitivity and specificity of $100 \%$ and $89 \%$. Moreover, $0.81,72 \%$ [Fig-3(a)] and $78 \%$ were the values for AUC, sensitivity, and specificity for discriminating probable PCP versus colonizers [Fig-3(b)]. The area under curve (AUC), sensitivity, and specificity were $0.85,75 \%$ and $78 \%$ respectively [Fig-3(c)] when colonizers were differentiated from both definiteprobable PCP taken together the cut-off of 7015 copies $/ \mathrm{ml}$.

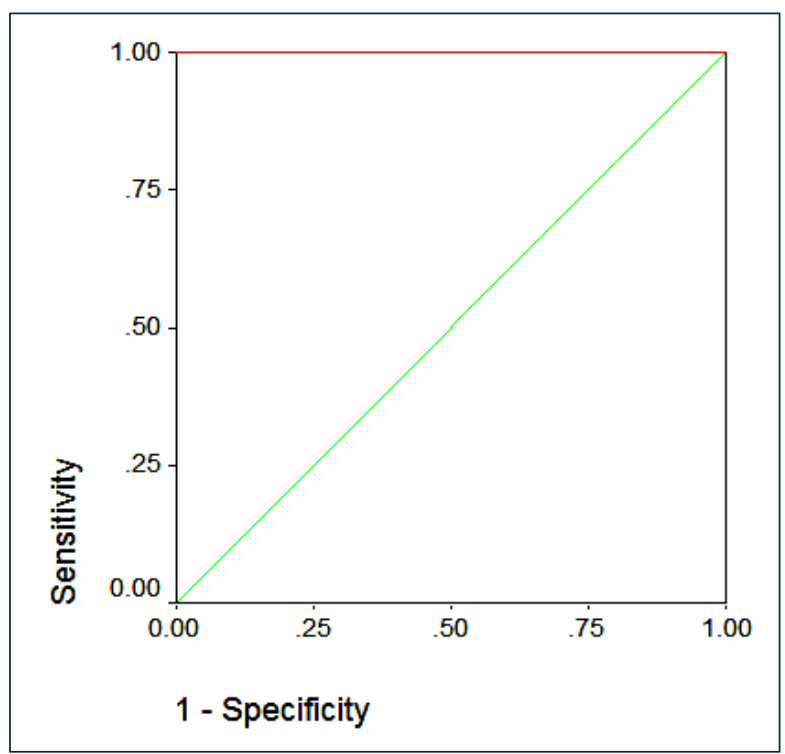

Fig. 3a- ROC curve for definite PCP and colonizers

The arbitrary cut-off value of 13950 copies $/ \mathrm{ml}$ was used to differentiate definite PCP from colonizers. The AUC, sensitivity and specificity were $1,100 \%$ and $89 \%$.

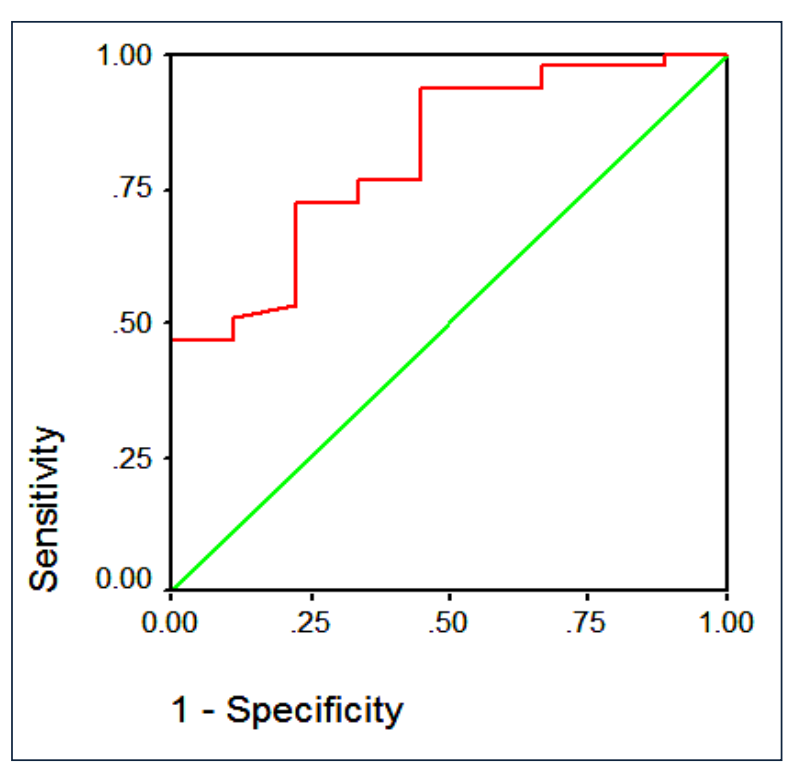

Fig. 3b- ROC curve for probable PCP and colonizers.

The arbitrary cut-off value of 6580 copies $/ \mathrm{ml}$ was used to differentiate probable PCP from colonizers. The AUC, sensitivity and specificity were $0.81,72 \%$ and $78 \%$.

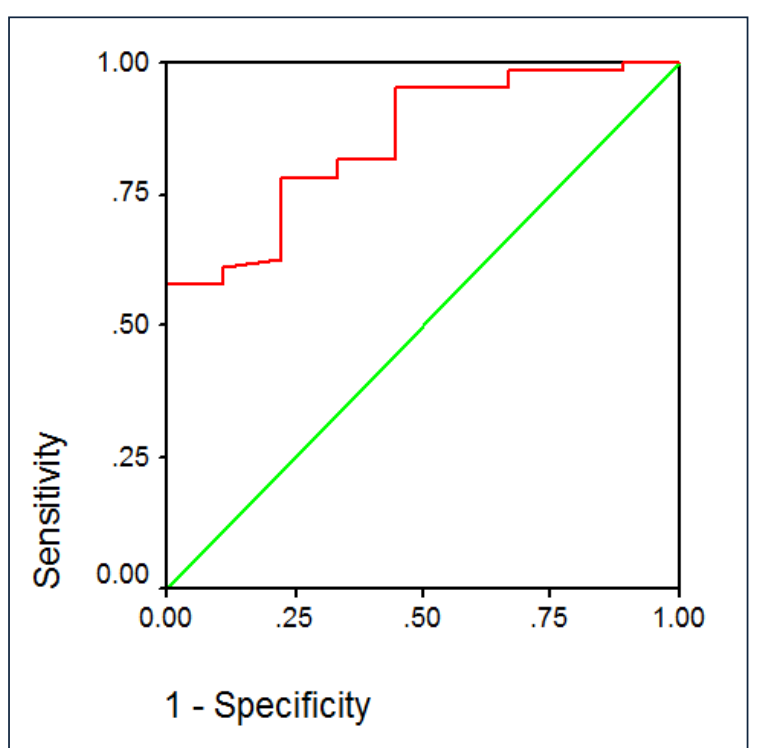

Fig. 3c- ROC curve for definite PCP, probable PCP and colonizers. The arbitrary cut-off value of 7015 copies $/ \mathrm{ml}$ was used to differentiate definite PCP + probable PCP from colonizers. The AUC, sensitivity and specificity were $0.85,75 \%$ and $78 \%$.

\section{Discussion}

Microscopic demonstration of $P$. jirovecii considered as standard method for the diagnosis of PCP. But microscopic demonstration suffers with the problem of lower sensitivity thus encountered with the problem of false negativity. However, with the introduction of PCR assays in the late 90s, such impaired sensitivity related issues have been overcome. Moreover, these conventional PCR based assays may have the problem of false positivity or these PCR assays are positive among those individuals that show no clinical signs and symptoms of Pneumocystis pneumonia. Such cases are commonly known as colonizers, asymptomatic individuals or patients with subclinical infection [17].

Concerns related to these issues lead to the development and employment of more advanced and rapid qPCR assays. Since, the first application of qPCR assay for the detection of PCP has been reported a number of researchers have explored variety of $P$. jirovecii specific genes for the detection and quantification.

In the present study, we classified the PCP positive patients into three groups based on the results of microscopy, PCR assay, clinical findings and response to treatment. Further, qPCR assay targeting Beta-tubulin (single copy) gene of $P$. jirovecii genome allowed us to know the exact load of the organisms in the clinical sample. The copy numbers of the definite PCP patients were significantly higher than the copy number of the colonizers, with an AUC, sensitivity and specificity (1,100\% and $89 \%)$. However, when probable PCP were compared with colonizers, and, combination of definiteprobable PCP together with colonizers the AUC, sensitivity and specificity were $0.81,72 \%, 78 \%$ and $0.85,75 \%, 78 \%$ respectively. Thus patients having less than 7015 copies/ml may be considered as colonizers [Fig-3(c)]. It was observed that the copy numbers between probable group of patients and colonizers were overlapping and a clear distinction could not be made. Therefore, in the present study, there was clear discrimination between the load of the definite PCP and colonizers with $P$. jirovecii and was statistically significant. However, there was an overlap between the load of the 
Probable PCP and colonizers. Consequently, there was a greyzone between probable PCP patients and colonizers.

Several, previous studies have reported a broad range of qPCR based cut-off values that do not efficiently made the discrimination between PCP patients with colonizers. Larsen et al used an arbitrary cut-off value of 10 copies/reaction for discrimination between infection and colonization [8]. However, applying this cut-off the false positive detection rate fell at the cost of an increase in false negative results. Flori, et al [18] found that a cut-off to differentiate asymptomatic carriage from PCP could not be established as there was an overlap between the two groups and sample with $<10^{3}$ copies of DNA per capillary could be a chronic carrier. Huggett, et al developed and evaluated q-PCR assay targeting single copy HSP70 gene and found that a cut-off of $>10$ copies/reaction, showed clinical sensitivity of $98 \%$ and specificity of $96 \%$ [9]. Furthermore, they said that load of organism in those with PCP, was not associated with disease severity and outcome of the diseases. Alanio, et al proposed two cut-off values of 120 and $1900 \mathrm{TFEq} / \mathrm{mL}$ to discriminate active pneumonia from colonization, with a grey zone between them [19]. Matsmura, et al used 1300 copies per ml as a cut-off to discriminate between definite PCP and colonizers with $P$. jirovecii [20]. Muhlethaler, et al proposed that $q-P C R$ values of between 1 to $1,450 P$. jirovecii per $\mathrm{ml}$ were associated with both colonization and infection; thus, a cut-off between the two conditions could not be established [21]. Maillet, et al also used two cutoff values to discriminate between diseased and colonizers with a grey zone between them [22].

This study had certain limitations like, the samples under study were non-homogenized i.e. BALF and IS. Furthermore, when the BALF and IS samples were analyzed separately, it was observed that there was only one sputum sample among definite PCP patients and there was no induced sputum sample among colonizers with $P$. jirovecii. The majority of the IS samples were among probable group of patients and the copy number was significantly higher in definite than in probable PCP patients. In-addition, the copy numbers were higher in probable PCP patients than in colonized patients, but the difference was again not statistically significant. This might be attributed due to the less number of patients among definite and colonizers group of patients.

Second, we had non-homogenized population under study. As stated earlier by Sing, et al that HIV associated PCP patients had higher organism burden as compared to non-HIV immunocompromised patients [23]. Therefore, the cut-off value to discriminate between definite, probable and colonizers ideally should be established separately for both HIV associated PCP patients and non-HIV associated.

Third, few of these patients were already on anti-PCP prophylaxis, therefore the organism burden among those patients might be lesser than that of naïve patients. As a result the cut-off would be different for both these group of individuals, so the population under study preferably should be naïve. Larsen, et al also observed similar results during the study on oral wash samples [24].

In conclusion, from the present study we observed that qPCR assay had high accuracies in differentiating definite PCP from colonization with $P$. jirovecii and moderate accuracies in differentiation between probable PCP and colonization. These results revealed that clinical, radiological and response to treatment should always be taken into consideration along with qPCR values especially among probable PCP patients and colonizers.

\section{Acknowledgement}

We have no potential conflicts of interest, and the financial assistance was provided by Indian Council of Medical Research (ICMR) to support the designed work.

\section{Ethical Clearance}

The study was approved by the institute's research and ethics committee.

Conflicts of Interest: None declared.

\section{References}

[1] Thomas C.F.Jr., Limper A.H. (2004) N. Engl. J. Med., 350(24), 2487-2498.

[2] Kovacs J.A., Hiemenz J.W., Macher A.M,, Stover D., Murray H.W., Shelhamer J., Lane H.C., Urmacher C., Honig C., Longo D.L., Parker M.M., Natanson C., Parrillo J.E., Fauci A.S., Pizzo P.A., Masur H. (1984) Ann. of Int. Med., 100(5), 663-671.

[3] Procop G.W., Haddad S., Quinn J., Wilson M.L., Henshaw N.G., Reller L.B., Artymyshyn R.L., Katanik M.T., Weinstein M.P. (2004) J. Clin. Microbiol., 42(7), 3333-3335.

[4] Nüesch R., Bellini C., Zimmerli W. (1999) Clin. Infect. Dis., 29 (6), 1519-1523.

[5] Hardak E., Brook O., Yigla M. (2010) Lung, 188(3), 159-163.

[6] Limper A.H., Offord K.P., Smith T.F., Martin W.J.II (1989) Am. Rev. Respir. Dis., 140(5), 1204-1209.

[7] Azoulay E., Bergeron A., Chevret S., Bele N., Schlemmer B., Menotti J. (2009) Chest, 135(3), 655-661.

[8] Larsen H.H., Kovacs J.A., Stock F., Vestereng V.H., Lundgren B., Fischer S.H., Gill V.J. (2002) J. Clin. Microbiol., 40(8), 2989 2993.

[9] Huggett J.F., Taylor M.S., Kocjan G., Evans H.E., Morris-Jones S., Gant V., Novak T., Costello A.M., Zumla A., Miller R.F. (2008) Thorax, 63(2), 154-159.

[10]Matsumura Y., Ito Y., linuma Y., Yasuma K., Yamamoto M., Matsushima A., Nagao M., Takakura S., Ichiyama S. (2012) Clin. Microbiol. Infect., 18(6), 591-597.

[11]Lee C.H., Lu J.J., Bartlett M.S., Durkin M.M., Liu T.H., Wang J., Jiang B., Smith J.W. (1993) J. Clin. Microbiol., 31(3), 754757.

[12]Wakefield A.E., Pixely F.J., Banerji S., Sinclair K., Miller R.F., Moxon E.R., Hopkin J.M. (1990) Lancet, 336(8713), 451-453.

[13]Nahimana A., Francioli P., Blanc D.S., Bille J., Wakefield A.E., Hauser P.M. (2000) J. Eukaryot. Microbiol., 47(4), 368372.

[14]Brancart F., Rodriguez-Villalobos H., Fonteyne P.A., PeresBota D., Liesnard C. (2005) J. Microbiol. Methods, 61(3), 381387.

[15]Morris A., Wei K., Afshar K., Huang L. (2008) J. Infect. Dis., 197 (1), 10-17.

[16]DeLong E.R., DeLong D.M., Clarke-Pearson D.L. (1988) Biometrics, 44(3), 837-845.

[17]Peterson J.C., Cushion M.T. (2005) Curr. Opin. Microbiol., 8(4), 393-398.

[18]Flori P., Bellete B., Durand F., Raberin H., Cazorla C., Hafid 
J., Lucht F., Sung R.T. (2004) J. Med. Microbiol., 53(7), 603607.

[19]Alanio A., Desoubeaux G., Sarfati C., Hamane S., Bergeron A., Azoulay E., Molina J.M., Derouin F., Menotti J. (2011) Clin. Microbiol. Infect., 17(10), 1531-1537.

[20]Matsumura Y., Shindo Y., linuma Y., Yamamoto M., Shirano M., Matsushima A., Nagao M., Ito Y., Takakura S., Hasegawa Y., Ichiyama S. (2011) BMC Infect. Dis., 25(11), 76.

[21]Mühlethaler K., Bögli-Stuber K., Wasmer S., von Garnier C., Dumont P., Rauch A., Mühlemann K., Garzoni C. (2012) ERJ, 39(4), 971-978.

[22]Maillet M., Maubon D., Brion J.P., François P., Molina L., Stahl J.P., Epaulard O., Bosseray A., Pavese P. (2014) Eur. J. Clin. Microbiol. Infect. Dis., 33(3), 331-336.

[23]Sing A., Trebesius K., Roggenkamp A., Rüssmann H., Tybus K., Pfaff F., Bogner J.R., Emminger C., Heesemann J. (2000) J. Clin. Microbiol., 38(4), 1461-1467.

[24]Larsen H.H., Huang L., Kovacs J.A., Crothers K., Silcott V.A., Morris A., Turner J.R., Beard C.B., Masur H., Fischer S.H. (2004) J. Infect. Dis., 189(9), 1679-1683. 
